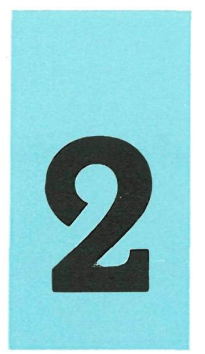

\title{
museds en Mä́xitot
}

P. RAMIREZ VAZQUEZ y R. MIJARES A., arquitectos

$142-50$

\section{simopsis}

\section{Museo de arte Moderno, en la Ciudad de México}

El conjunto construido consta de dos edificios: el Museo de Arte y la Galería de Arte. El primero se ha resuelto en dos plantas, y alberga: seis salas circulares para exposiciones, unidas entre sí por los servicios comunes (públicos, administrativos y de entretenimiento), y un gran vestíbulo, también circular, de doble altura. El segundo se ha organizado asimismo en dos niveles, y consta de una sala circular para exposiciones en planta alta y servicios en planta baja, ligando ambas zonas por medio de un vestíbulo central, que los comunica al exterior. La expresividad formal de los dos cuerpos construidos y el paraje elegido para emplazarlos constituyen un acierto plástico y de ambientación.

\section{Museo en Ciudad Juárez}

Comprende este edificio: un cuerpo central, de planta circular, que alberga: cuatro salas de exposiciones; y otro, concéntrico con el anterior, que contiene dos amplias salas de exposición. El acertado juego de volúmenes, formas, y texturas, así como su colocación sobre una gran lámina de agua, imprimen a este Museo un especial atractivo.

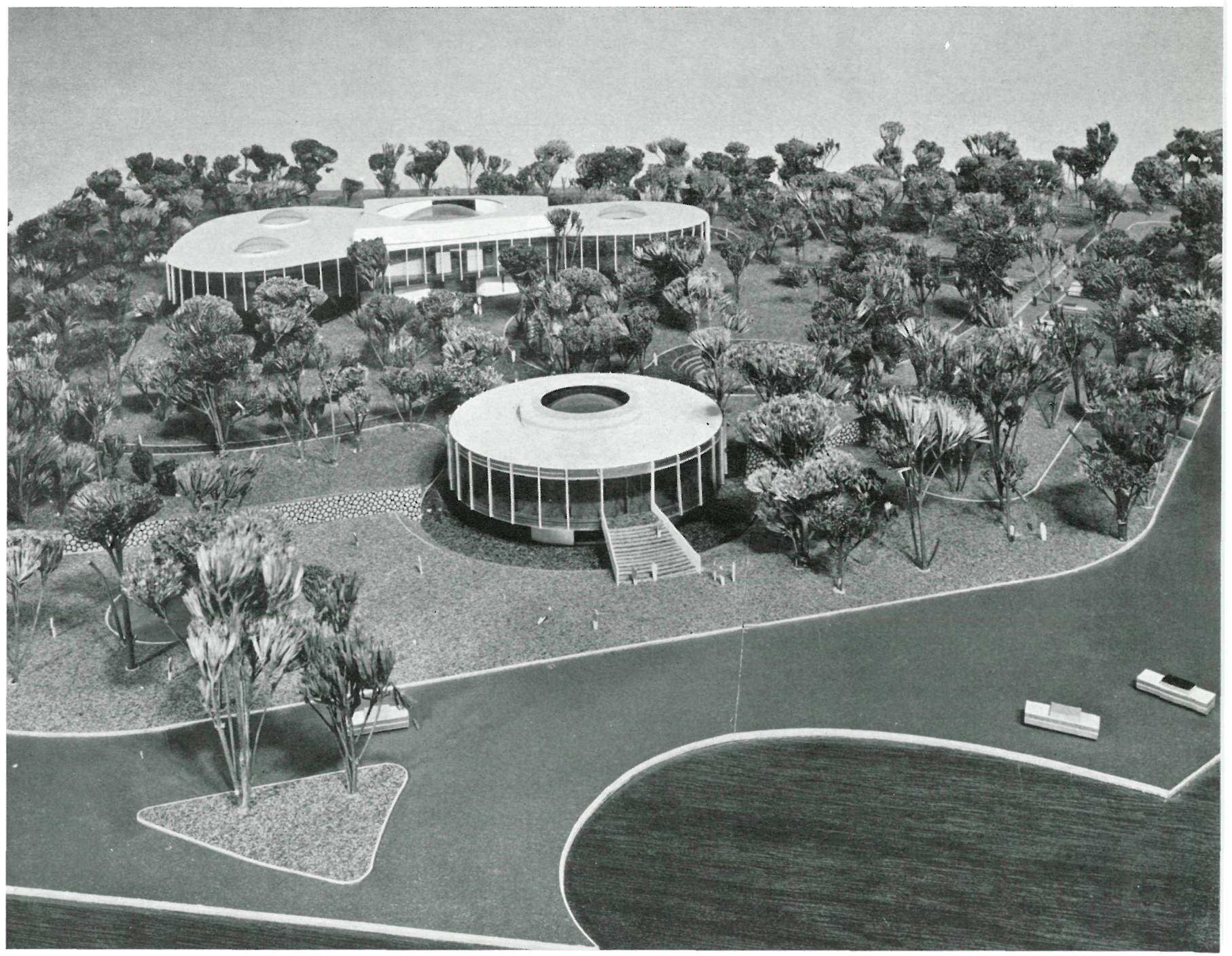




\section{Museo de Arte Moderno en la Ciudad de Méxieo}
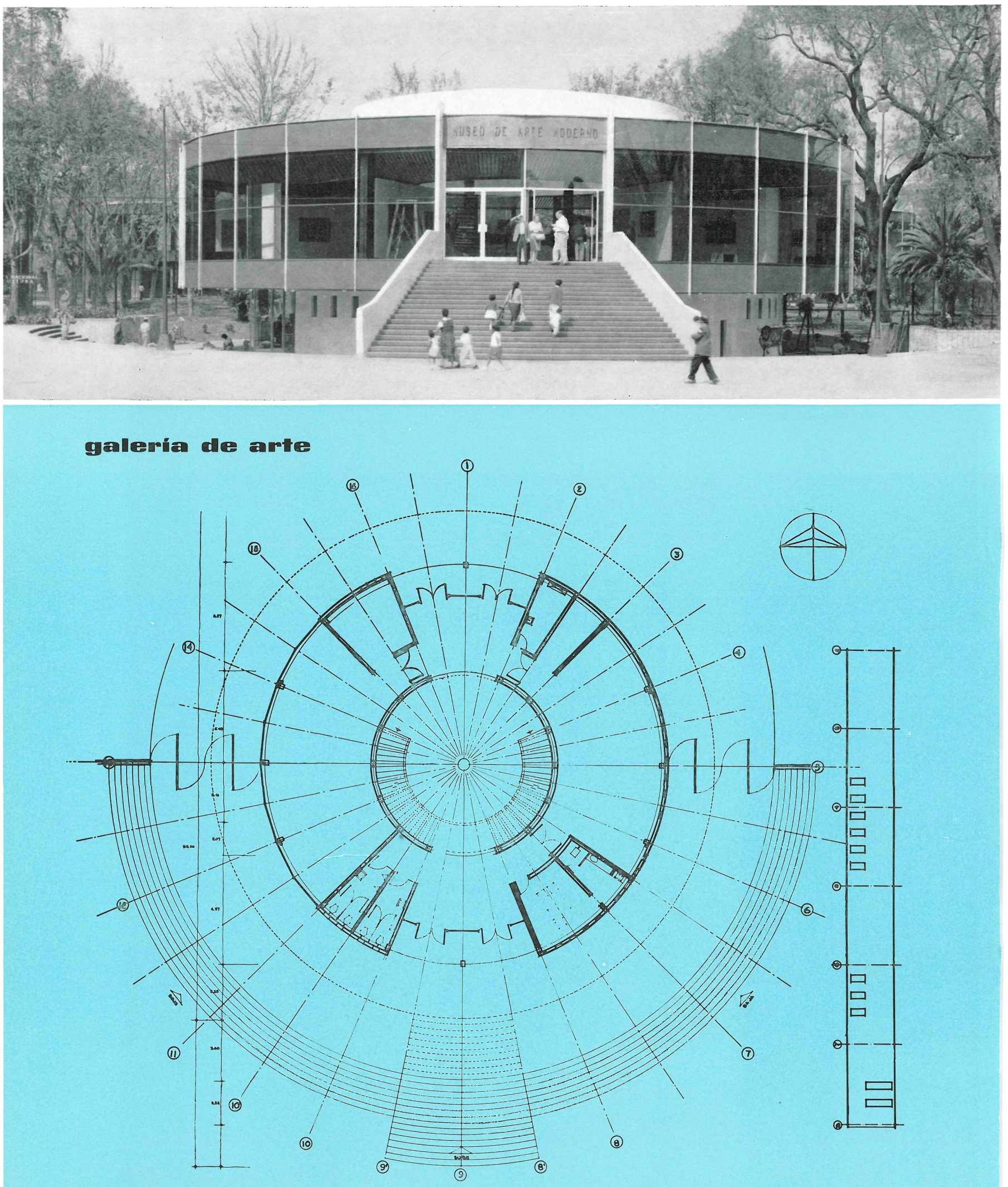

planta semisótamo 


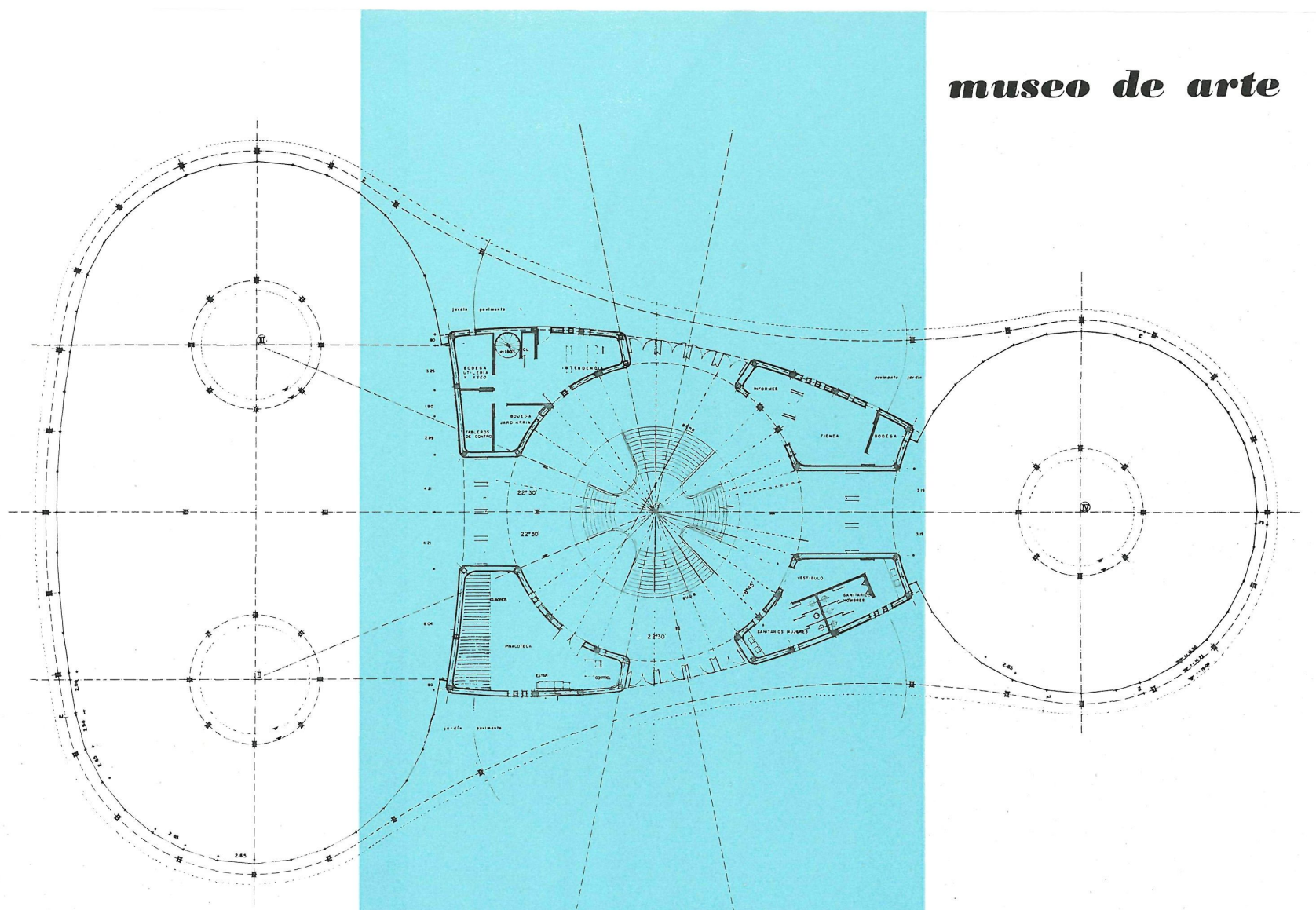

planta baja

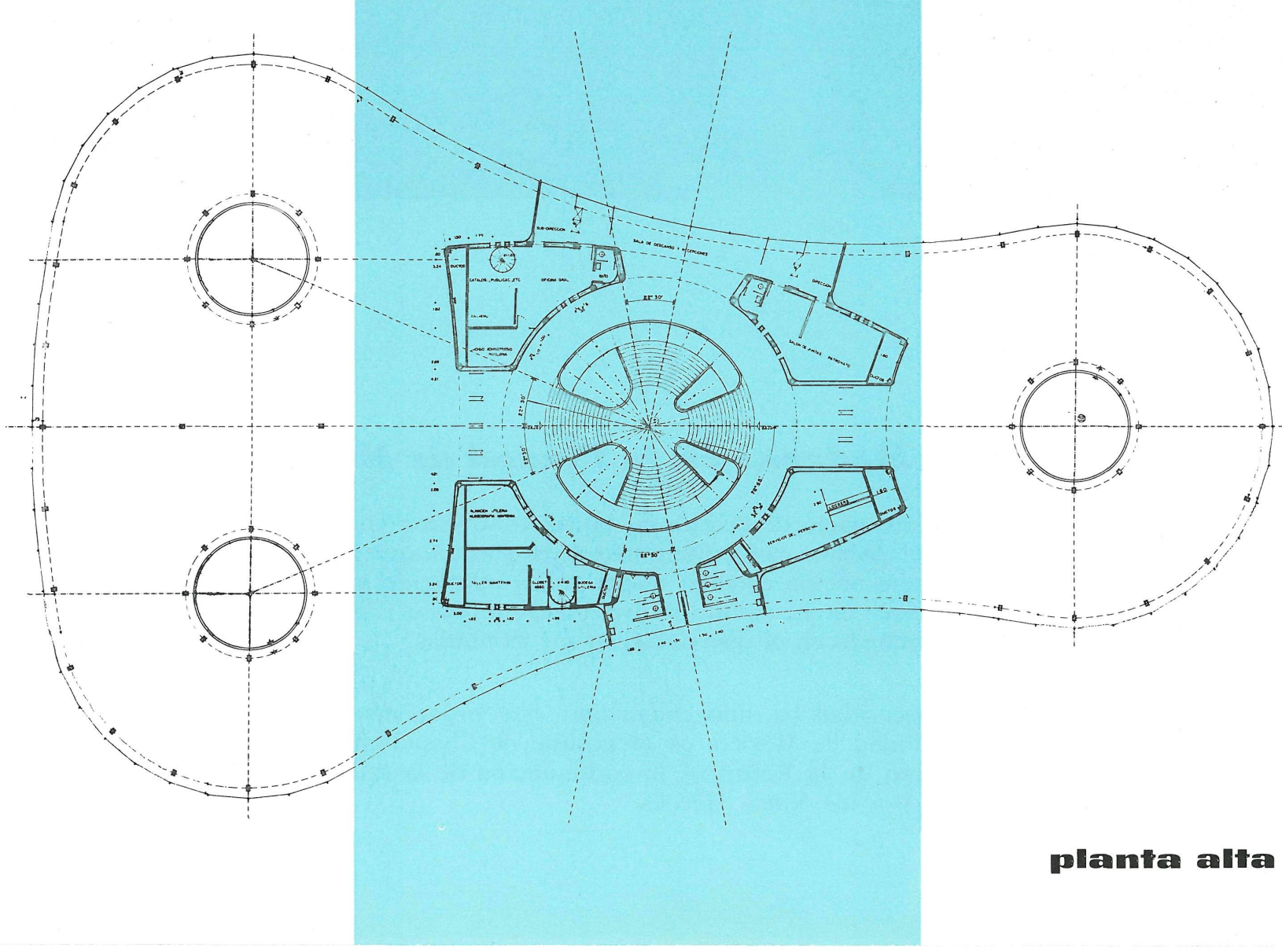




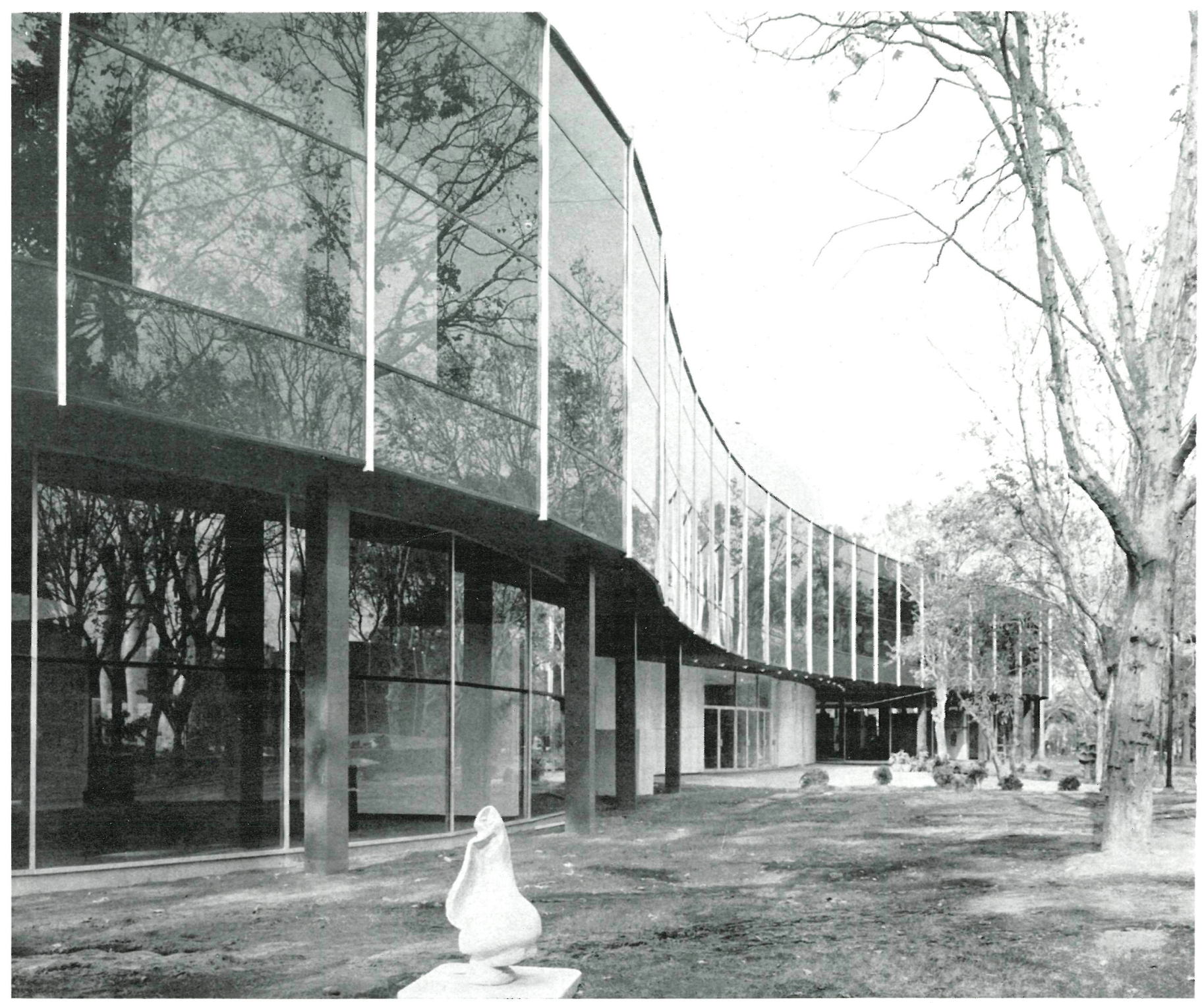

\section{Museo de Arte Moderno en la Ciudad de Méxieo}

El proyecto de este Museo nació de la idea de poder centralizar en un solo núcleo el gran tesoro artístico del México contemporáneo, pues sucedía que la casi totalidad de las obras de arte en dicha nación estaban dispersas en manos de particulares, y éstos no podían darlas a conocer en su conjunto al público mejicano y extranjero mientras no existiese un local adecuado en el que pudieran ser exhibidas.

Para satisfacer dicha necesidad ha sido construido este organismo cultural, llamado Museo de Arte de la Ciudad de México, en el bosque de Chapultepec, en la manzana que queda entre el Paseo de la Reforma, la continuación de la calle de la Milla y los monumentos a Bolívar y a los Niños Héroes. 
El lugar escogido se adapta al Plan General existente para el mejoramiento de las condiciones del bosque, en el que se trata de conjugar el esparcimiento con la cultura, siendo ideales su emplazamiento y fácil acceso.

Constituyen el conjunto dos edificios: el Museo de Arte y la Galería de Arte. El primero es el Museo propiamente dicho; en el que se exponen en forma permanente un número aproximado de 1.200 de las mejores obras de pintura, escultura, dibujo y grabado de arte contemporáneo mejicano.

Dicho Museo -desarrollado en dos plantas- alberga: seis salas circulares para exposiciones, unidas entre sí por los servicios comunes (públicos, administrativos y de mantenimiento); y un gran vestíbulo, también circular, de doble altura, al que se llega del exterior por un lado desde el Paseo de la Reforma y por el otro desde el edificio de la Galería.

En el edificio menor -la Galería de Arte-, con capacidad para exponer unas 200 obras artísticas, se celebran exposiciones temporales de obras, tanto de nuevos valores como de artistas consagrados -mejicanos y extranjeros-. Se ha resuelto también en dos niveles, y consta de una sala circular para exposiciones en planta alta, y los servicios en planta baja, ambos ligados por un vestíbulo central que los comunica al exterior.

Los exteriores, que han sido tratados paisajísticamente, presentan jardines con paseos y plazuelas que crean espacios adecuados para exponer esculturas de tipo monumental, al mismo tiempo de servir para formar una pantalla aislante de ruidos que ayuda a conseguir la tranquilidad precisa para una sala de exposición.

El emplazamiento de los edificios fue determinado considerando, principalmente, las funciones que en su interior se iban a desarrollar, pero respetando los árboles existentes y aprovechando únicamente los claros que quedaban.

Sus formas curvas nacieron de las siguientes consideraciones:

- las salas de exposición son de planta circular, porque dicha forma facilita la circulación y evita los rincones perdidos;

2 los volúmenes curvos están más de acuerdo con los espacios continuos, pero cambiantes, que forman la gran cantidad de árboles dispersos irregularmente en el terreno;

3 dichos volúmenes no impiden que se siga manteniendo el aspecto de bosque del lugar, sino que, por el contrario, las fachadas curvas dan la impresión de reducir dichos volúmenes porque nunca se ven desde ningún punto en todo su desarrollo.

El tratamiento dado a las fachadas obedeció, por un lado, a las razones anteriormente mencionadas, ya que el cristal, con sus reflejos, absorbe los edificios en el follaje; y por otro lado, vino impuesto por la conveniencia de ampliar el campo visual de las obras de arte hacia el exterior para que éstas lancen el señuelo de su atractivo a las personas que pasan por allí, invitándoles a entrar; y también para que, una vez dentro puedan dirigir libremente la vista hacia el exterior, y descansar de la concentración artística en la contemplación de las frondas y el paisaje circundante. 


\section{Museo en Ciudad Juánez}

El edificio consta de dos cuerpos: uno central, de planta circular; y otro, concéntrico con el anterior, unido a él mediante un paso cubierto.

Los ingresos al mismo se realizan, mediante una rampa, al núcleo central; y por medio de una amplia escalinata, al ala concéntrica.

El núcleo central alberga: cuatro salas de exposiciones, el vestíbulo, la oficina de la dirección y dos pequeños locales anexos; las compartimentaciones no son continuas y cerradas, sino parciales, y más bien de tipo psicológico.

El ala concéntrica aloja: un vestíbulo, en conexión con el paso anteriormente mencionado de unión con el núcleo central; y dos amplias salas de exposición; una terraza cubierta, en comunicación con el entorno paisajístico exterior; y un local-taller.

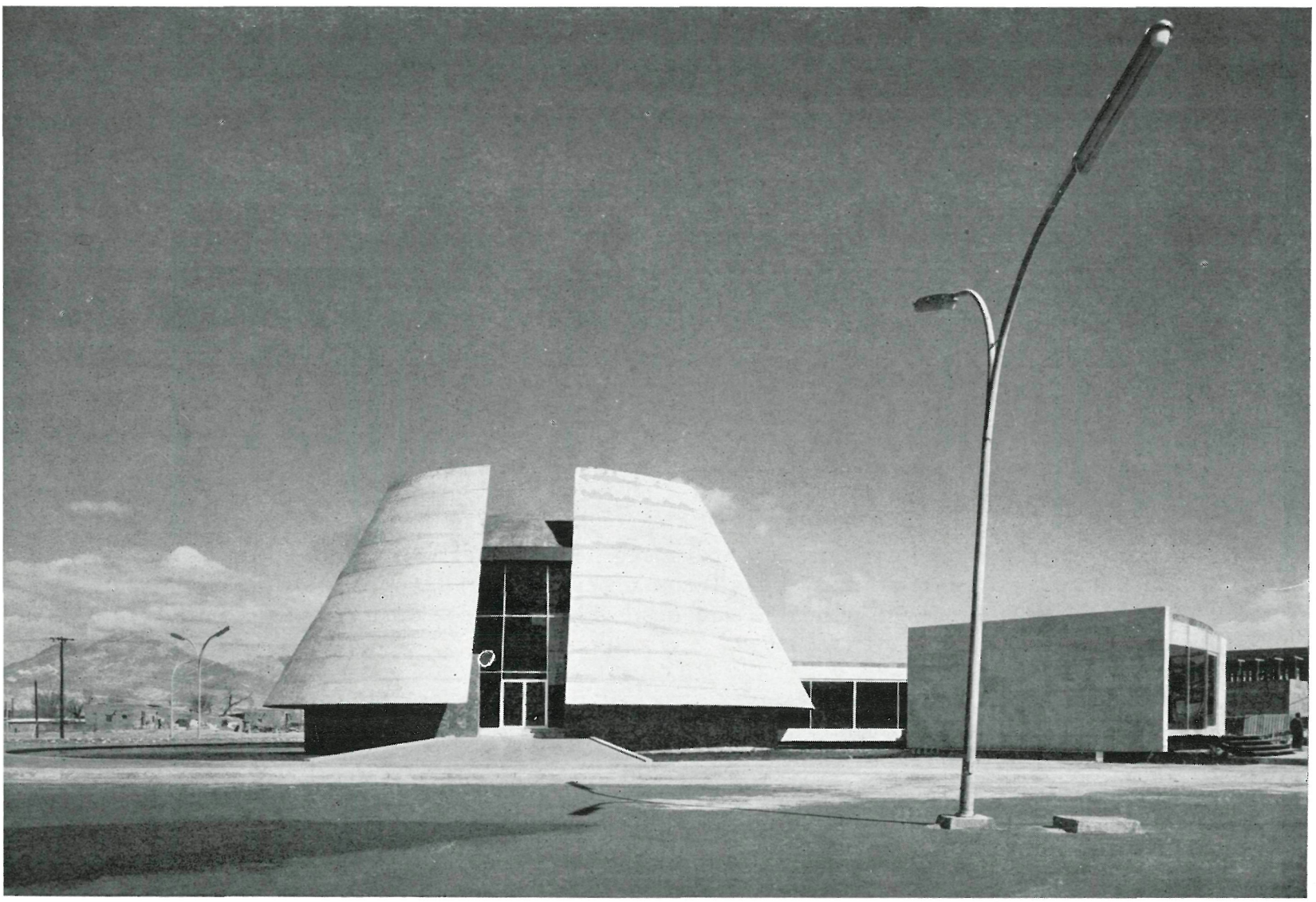


planta principal

1. Taller.-2. Espejo de agua.3. Sala 5.-4. Vestíbulo.-5. Paso. 6. Sala 3.-7. Sala 4.-8. Bodega la 2.-12 Sala 6.-13. Acceso14. Rampa.-15. Terraza.-16. Maqueta.

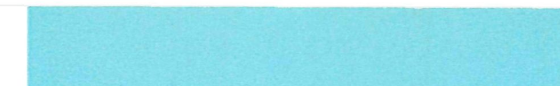
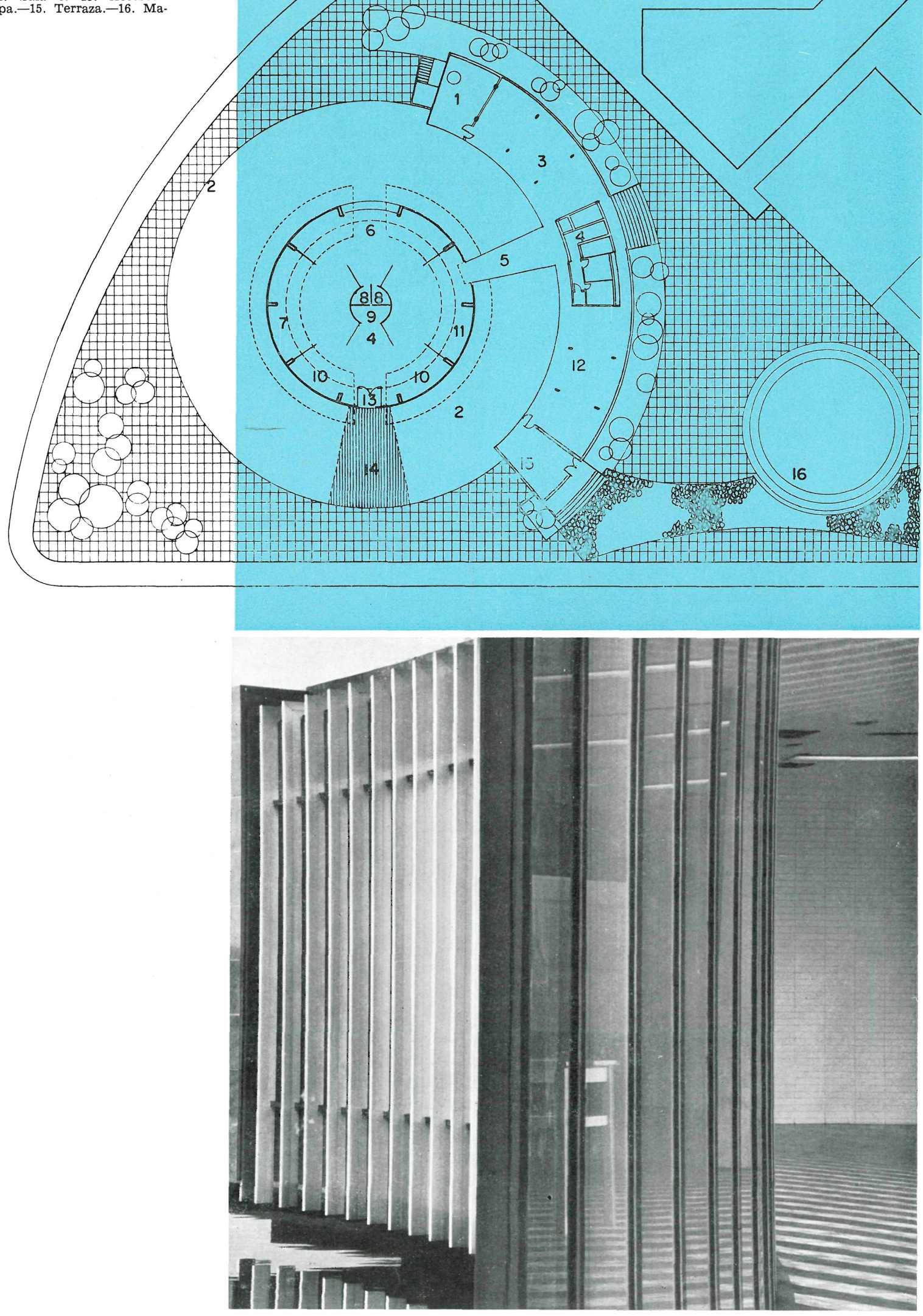


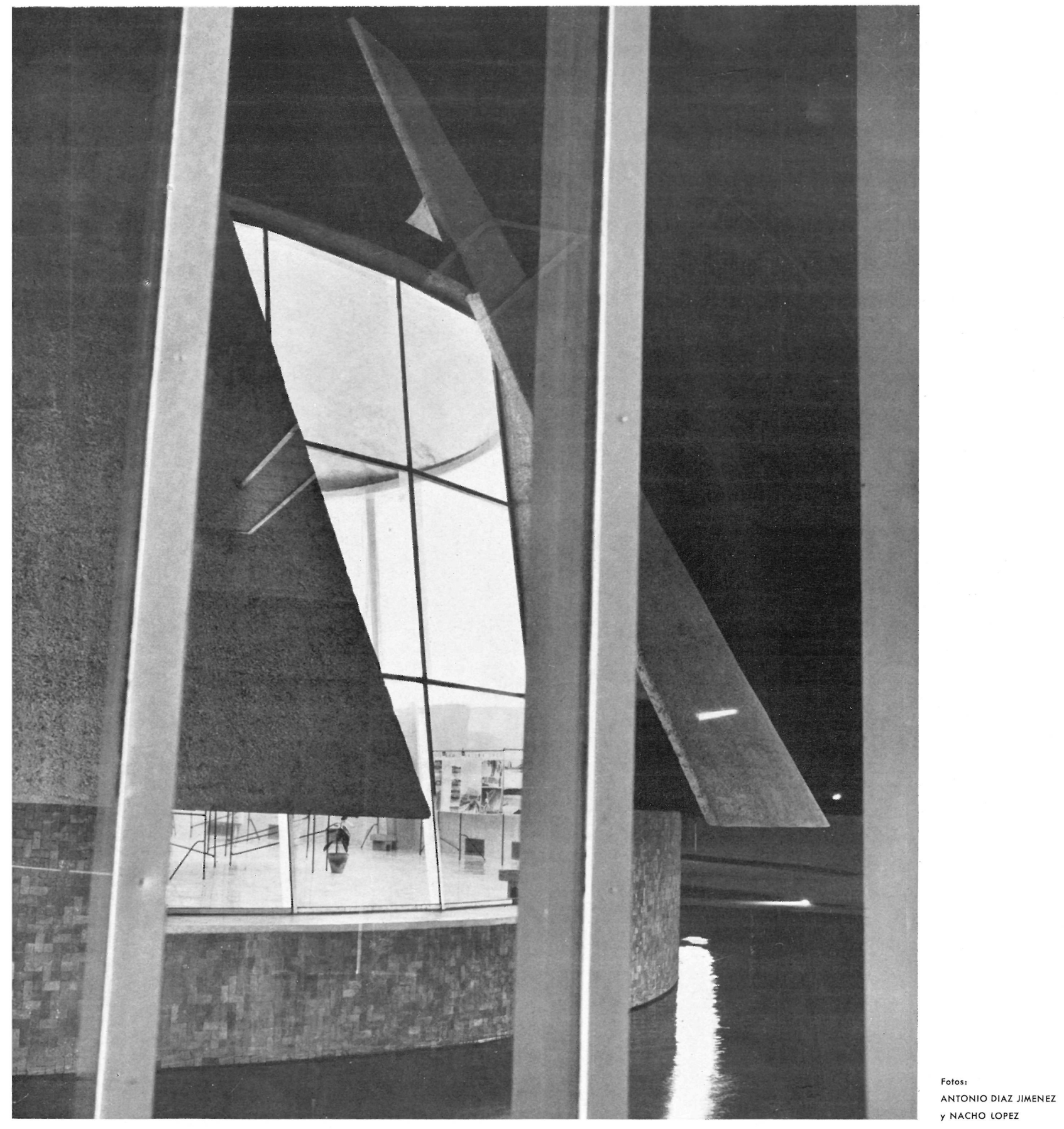

Son de destacar, en este edificio, el tratamiento dado a sus fachadas; la forma de sus volúmenes; la armónica combinación de las texturas de los materiales utilizados en los revestimientos; la acertada incorporación de las grandes superficies acristaladas de los cerramientos, que permiten disfrutar, en el interior, de la iluminación óptima exigida por este tipo de edificios.

Como elemento valorizador de los volúmenes, y tranquilizador a la vista, ha sido creada una gran lámina de agua, que rodea el núcleo central, interrumpida únicamente por la rampa y el paso cubierto.

Adaptado por J. M. Rubio. 


\section{Deux muscées au Mexique}

P. Ramírez Vázquez et R. Mijares A., architectes

1. Musée d'Art Moderne, à Mexico

Il s'agit de deux édifices qui comprennent le musée d'Art et la Galerie d'Art.

Le premier, de deux niveaux, abrite six salles circulaires pour expositions, reliées entre elles par les services communs (publics, administratifs et d'entretien) et un grand vestibule, également circulaire, de double hauteur.

Le second, qui se compose également de deux niveaux, comprend une salle circulaire pour expositions à l'étage supérieur et les services situés au rez-de-chaussée. Ces deux zones sont reliées par un vestibule central qui les fait communiquer avec l'extérieur. L'endroit choisi pour la construction de ces deux édifices et la qualité expressive de leurs formes constitutent un ensemble heureusement conçu, tant du point de vue plastique que du point de vue de l'ambiance.

\section{Musée à Ciudad Juárez}

Cet édifice comprend un corps central, en plan circulaire, qui abrite quatre salles d'exposition, et un autre corps, concentrique avec l'antérieur, qui comporte deux amples salles d'exposition.

Le jeu heureux des volumes, formes et textures, ainsi que leur emplacement sur une grande nappe d'eau, donnent à ce musée un caractère particulièrement attrayant.

\section{Two Musseums in Mexico}

P. Ramírez Vázquez \& R. Mijares, A., architects

\section{Modern Art Museum, at Mexico City}

This consists of two buildings, the Art Museum and the Art Gallery.

The first has two floor levels and contains six circular halls for exhibitions, linked together by common utilities (public, administrative and maintenance offices), and by a large vestibule, which is also round and extends up to the second floor.

The art gallery also has two floors, and has a circular exhibition hall on the second floor, and various services in the lower floor. A central vestibule connects both floors and the exterior.

The formal expressivity of both blocks and the surrounding site are highly impressive because of their harmony and plasticity.

\section{Ciudad Juarez Museum}

This museum has a central block, of circular base, which is occupied with four exhibition halls, and a second block, concentric with the first one, which also contains a number of exhibition rooms.

The fortunate arrangement of volumes, their shape and texture, and their emplacement in the centre of a lake, make this an especially attractive building.

\section{Zwei Museen in Mexice}

P. Ramírez Vázquez und R. Mijares A., Architekten

1. Modernekunstmuseum in Ciudad de México

Der gebaute Komplex besteht aus zwei Gebäude: das Kunstmuseum und die Kunstgalerie.

Das erste besthet aus zwei Geschosse und beherbergt sechs kreisförmige Säle für Ausstellungen untereinander verbunden durch die Publikums-, Verwaltungs- und Aufenthaltsräume und eine grosse kreisförmige Halle mit doppelter Höhe.

Die zweite besteht aus zwei Stockwerke. Im Obergeschoss befindet sich ein grosser kreisförmiger Saal für Ausstellungen und im Erdgeschoss liegt die Diensträume.

Der Ausdruck der zwei Gebäude und die gewähIte Landschaft geben einen besonderen Charakter.

\section{Museum in Ciudad Juárez}

Das Gebäude besthet aus einem zentralen kreisförmigen Körper, der vier Ausstellungsräume beherbergt, und einem anderen konzentrisch mit dem letzten, der zwei grossen Ausstellungsräume enthält.

Die Form und Texturen so wie seine Lage geben diesem Museum einen besonderen Charakter. 